\title{
Estudo químico das sementes do Cupuaçu
}

\author{
M. N. Lima Vasconcelos (") \\ M. Leão da Silva (") \\ J. G. Soares Maia ( ${ }^{\star}$ ) \\ O. R. Gottlieb (**)
}

\begin{abstract}
Resumo
A análise comparativa das sementes das Sterculiaceas cupuaçu (Theobroma grandiflorum Schum.) e cacau (Theobroma cacao L.) mostrou, com respeito à gordura, diferenças apenas com respeito à composição quantitativa da fração ácida dela liberada (ácidos palmítico 5,8:32,8, esteárico $38,3: 35,5$, oléico 42,8:29,6, araquídico 4,8:1,0, linoléico $8,3: 1,1$; $\%: \%$ respectivamente) e, com respeito às purinas, presença do ácido 1,3,7,9-tetrametilúrico no cupuaçu em substituição à cafeina, à teobromina e à teofilina do cacau.
\end{abstract}

O cupuaçu (Theobroma grandiflorum Schum., Sterculiaceae), uma das mais importantes fruteiras tipicamente amazônicas, é encontrado espontaneamente nas matas de terra firme e várzea alta na parte sul e leste do Pará. Abrangendo as áreas do médio Tapajós, rio Xingu e rio Guamá, alcança o noroeste do Maranhão principalmente nos rios Turiaçu e Pindaré ( $\mathrm{Cal}$ zavara, 1970). Mais recentemente foi encontrado ainda, provavelmente em estado nativo, no alto rio Itacaiúnas (Marabá) na mata baixa como planta emergente, ultrapassando os 20 $\mathrm{m}$ de altura, e por ocasião da abertura da rodovia Transamazônica, na mata virgem rala e baixa, entre Altamira e Itaituba (Cavalcante, 1974).

O endocarpo carnoso do fruto do cupuaçu possui um sabor ácido peculiar que o torna apreciadíssimo sob forma de compotas, sucos, sorvetes e licores. Preparo e consumo destes produtos é praticamente restrito à Amazônia, sua exportação para o estrangeiro e mesmo para outras regiões do Brasil verificandose apenas èsporadicamente.
Por ocasião da separação da polpa sobra a casca do fruto, que supomos ser usada localmente e em pequena escala como ração para gado e adubo, à semelhança da casca do ca. cau (Dittmar, 1953), e as sementes. Estas são reputadas como ótima matéria-prima para a preparação de chocolate branco de fina qualidade (Calzavara, 1970) e consideradas um alimento substancial por seu teor em amido $(15 \%)$, proteina $(15 \%)$ e gordura $(50 \%)$ (Cuatrecasas, 1964). Ao que nos consta, porém, continuam constituir refugo, não sofrendo aplicação.

Mesmo assim não foram ignoradas pelo fitoquimico, em vista, principalmente, da afinidade botânica do cupuaçu com o cacau $T$. cacao L.), planta de grande importância econômica. Já em 1921 e 1922 vários autores, citados por Jamieson (1943), registraram as constantes físico-químicas da gordura das sementes do cupuaçu, que descrevem como quase incolor, isenta de cheiro e gosto e, provavelmente, édula.

\section{PARTE EXPERIMENTAL}

Isolamento dos constituintes. Sementes de cupuaçu $(100 \mathrm{~g})$ foram secas em estufa a $55^{\text {? }}$ até peso constante, operação em que perderam $27,8^{\circ}$ de água, trituradas e extraídas em aparelho tipo soxhlet com n-hexano. Em seguida foram misturadas com $\mathrm{MgO}$ e aquecidas com água. A massa resultante foi clarificada por adição de $\mathrm{Pb}(\mathrm{OAc})^{2}$ e filtração. A solução por adição de $\mathrm{Pb}(\mathrm{Oac})_{2}$ e filtração. A solução aquosa resultante foi concentrada a $100 \mathrm{ml} \mathrm{em}$ evaporador rotativo e extraída com $\mathrm{CHCl}_{3}$.

\footnotetext{
(*) - Seção de Química de Produtos Naturais, Instituto Nacional de Pesquisas da Amazônia, Conselho Nacional de Desenvolvimento Científico e Tecnológico.

("*) - Laboratório de Produtos Naturais, Instituto de Química, Universidade de São Paulo.
} 
Por evaporação da solução clorofórmica resultou ácido 1, 3, 7, 9 - Tetrametilúrico. Por evaporação da solução hexânica resultou gordura (rend. $59,2 \%$ da semente).

Ácido 1,3,7,9-tetrametilúrico (2), cristais incolores, p.f. $227-229^{\circ}$ (recrist. em água) [Encontrado C, 47,79; H, 4,97; N, 24,59. $\mathrm{C}_{9} \mathrm{H}_{12} \mathrm{~N}_{4} \mathrm{O}_{3}$ requer C, 48,21; $\mathrm{H}, 5,39 ; \mathrm{N}, 24,99 \%$ ]. $>_{\text {Me oH }}(\mathrm{nm}): 232,293$ ( $\left.\varepsilon 3000,5300\right)$.

$\left(\mathrm{cm}^{-1}\right): 2950,1720,1650,1550,1490,1440,1390$. $1340,1300,1250,1120,1090,1050,1020,980$, $920,860,800,760$. ' $\mathrm{HMR}\left(\mathrm{CDCl}_{3}, \tau\right): 6,28$; 6,36; 6,40 e 6,60; bandas simples, 4 OMe. EM (m/e): $224(100 \%)$ M, 167 (40), 139 (35), 112 (8), 111 (9), 100 (10), 82 (80). P.f., IV e UV idênticos aos dados análogos publicados, cf. Sadtler, 1970.

Gordura. Saponificação $(5 \mathrm{~g}, \mathrm{KOH} 10 \mathrm{~N}$ em EtoH-EtO ${ }_{2} 3: 1$, refluxo, 2 h) foi seguida de adição de água e extração do insaponificável com petróleo leve. A solução aquosa foi acidificada $\epsilon$ re-extraída com petróleo leve. Esta solução foi separada e evaporada. Esterificação (Ham marstrand, 1966) $\left(5 \% \mathrm{H}_{2} \mathrm{SO}_{4}\right.$ em $\mathrm{MeOH}$, refluxo 2 h) dos ácidos residuais foi seguida de edição de água e extração com petróleo leve. Evaporaçăo do solvente forneceu os esteres metílicos dos ácidos da gordura. Estes foram identificados por CGL pelos seus tempos de retenção e determinados quantitativamente (padronização interna) em aparelho da Varian Aerograph, modelo 2848. Temperatura da coluna $215^{\circ} \mathrm{C}$, temperatura do detector $250^{\circ} \mathrm{C}$, temperatura do injetor $225^{\circ} \mathrm{C}$, atenuação $64 \times 10^{-9}$, velocidade do papel $1 \mathrm{~m} / \mathrm{min}$, quantidade de material injetado $1,0 \mu \mathrm{l}$, material da coluna DEGS (diethylene glycol succinate) em chromosorb W, espessura e tamanho da colu. na $1 / 8^{\prime \prime} \times 5^{\prime}$.

A análise comparativa das gorduras do cupuaçu e do cacau, constante do presente trabalho, mostra que a uma série de constante físicas e químicas (Tab. 1) comparắveis unem-se outras diferenciadoras, baseadas na composição química (Tab. 2) bastante diferente das duas. Para evitar que eventuais diferenças possam ser atribuídas a fatores climáticos (Berbert \& Alvim, 1972) foram analizadas gorduras extraídas de sementes de cupuaçu e de cacau originárias da mesma regiäo, arredores de Manaus. As análises se referem a amostras únicas, ficando o afastamento dos dados de valores médios, calculados com base em um número adequado de amostras, a ser determinado.

\section{TABELA 1}

Constantes físicas e químicas de gorduras de sementes de cupuaçu e cacau

\begin{tabular}{lll}
\hline \multicolumn{1}{c}{ Constantes } & Cupuaçu & Cacau \\
\hline $\mathrm{pH}$ & 5,7 & 6,3 \\
Ponto de fusão $\left({ }^{\circ} \mathrm{C}\right)$ & $32-34$ & $30-35^{\circ}$ \\
Lensidade específica $\left(25 / 25^{\circ} \mathrm{C}\right)$ & 0,9074 & $0,973^{*}$ \\
Indice de refração & 1,4583 & $1,4565-1,4570^{*}$ \\
Indice de acidez & 4,2 & $1-4^{* *}$ \\
Indice de iodo & 45,9 & $32-42^{* *}$ \\
Indice de saponificação & 174,6 & $192,198^{* *}$ \\
Insaponificáveis (\%) & 0,6 & $0,3-0,8^{* *}$ \\
\hline
\end{tabular}

\section{TABELA 2}

Composição percentual da mistura de ácidos graxos liberados da gordura de semente de cupuaçu e cacau

\begin{tabular}{|c|c|c|c|}
\hline \multicolumn{2}{|c|}{ Ácidos graxos } & \multirow{2}{*}{$\begin{array}{c}\text { Cupuaçu } \\
5,8\end{array}$} & \multirow{2}{*}{$\begin{array}{c}\text { Cacau } \\
32,8\end{array}$} \\
\hline Palmítico & $c_{16 / 0}$ & & \\
\hline Esteárico & $\mathrm{C}_{18 / 0}$ & 38,3 & 35,5 \\
\hline Oléico & $c_{18 / 1}$ & 42,8 & 29,6 \\
\hline Araquídico & $\mathrm{C}_{20 / 0}$ & 4,8 & 1,0 \\
\hline Linoléico & $\mathrm{C}_{18 / 2}$ & 8,3 & 1,1 \\
\hline
\end{tabular}

Willaman \& Schubert (1961) transcreveram a observação original de Freise (1935) segundo o qual a semente do cupuaçu, à semelhança de semente de cacau e de várias outras espécies de Theobroma, contém cafeína (1) e teobromina. Enquanto não tivemos dificuldade de confirmar este registro com respeito ao cacau, foram infrutíferos todos os nossos esforços para detetar (método de Holmes ex Gerritsma e Koers, 1953) cafeína, teobromina e teofilina nas sementes do cupuaçu. Em substituição isolamos uma outra purina, o ácido 1,3,7,9-tetrametilúrico (2). Este foi encontrado pela primeira vez como produto natural, por Johnson em 1937, nos resíduos da extração co. mercial da cafeína de "milhares de libras" de 
chá. Mais recentemente Wanner et alii (1975) isolaram a mesma substância de folhas jovens e frutos (pericarpo e sementes) de várias espécies de café, coletadas na África, e postula. ram que poderia tratar-se de um produto catabólico da cafeína. Esta hipótese é interessante em vista da comprovada ausência de quantidades substanciais de cafeína de espécies de Coffea de Madagascar e ilhas vizinhas (Wanner et alii, 1975), situação que possui paralelo no gênero Theobroma: presenças mutuamente exclusivas de cafeína no cacau e de ácido 1,3,7,9-tetrametilúrico no cupuaçu.<smiles>Cn1c(=O)c2c(ncn2C)n(C)c1=O</smiles>

(1)<smiles>Cn1c(=O)c2c(n(C)c1=O)n(C)c(=O)n2C</smiles>

(2)

\section{SUMMARY}

A comparative analysis of the seeds of the Sterculiaceae cupu (Theobroma grandiflorum Schum.) and cocoa (Treobroma cacao L.) showed, with respect to the fat only quantitative differences of the liberated acid fraction (palmitic 5.8:32.8, stearic $38.3: 35.5$, oleic $42.8: 29.6$, arachidic 4.8:1.0, linoleic $8.3: 1.1$ acids, $\%: \%$ respectively) and, with respect to purines, presence of 1,3,7,9-tetramethyluric acid in cupu in substitution to caffeine, theobromine and theophylline in cocoa.

\section{BIBLIOGRAFIA CITADA}

BERBERT, P.R.F. \& ALVIM, P. DE T.

1972 - Fatores que afetam o índice de iodo na manteiga do cacau no Brasil. Theobroma, 2(1):3-14.

BOEKENOOGEN, H.A.

1964 - Oils, fats and fat products. New York. Interscience Publishers, p. 23-36.

Calzavara, B.B.G.

1970 - Fruteiras: abieiro, abricozeiro, bacurizeiro, biribazeiro e cupuaçuzeiro. Culturas da Amazônia, Instituto de Pesquisas e Experimentação Agropecuárias do Norte, Belém, Pará, 1(2):3-14
Cavalcante, P.B.

1974 - Frutas comestíveis da Amazônia II. Museu Paraense Emílio Goeldi, Publicações Avulsas, 27:61-62.

Cuatrecasas, J.

1964 - Cacao and its aliies, a taxonomica revision of the genus Theobroma. Bulletin of United States National Museum, 35(6):438-439

DITTMAR, F.K.

1953 - Sobre o aproveitamento do cacau. En. genharia e Química, jan/fev, p. 1-5.

FREISE, F.W.

1935 - Vorkommen von Koffein in brasilianischen Heilpflanzen. Pharmazeutische Zentralhalle für Deutschland, 76:704.

Gerritsma, K.W. \& KoERs, J.

1953 - Determination of theobromine in cocoa residues. Analyst, 78:201-205

Hammarstrand, $\mathrm{K}$.

1966 - Gas chromatographic analysis of fatty acids. Varian Aerograph, applications laboratory. p. 1-16.

JAMIESON, G.S

1943 - Vegetable fats and oils. New York, Reinhold Publishing Corporation, p. 41-45.

JOHNSON, T.B.

1937 - Purines in the plant kingdom. The discovery of a new purine in tea. J. Am. Chem. Soc., 59:1261.

Kirschenbauer, H.G.

1944 - Fats and oils. New York, Reinhold Publishing Corporation, p. 128-129.

LE CONTE, P.

1939 - Sementes oleaginosas, bálsamos, resinas, essenciais, borrachas, gutas e balatas da floresta amazônica. 5. ed. Ministério do Trabalho, Indústria e $\mathrm{Co}$. mércio.

SADTLER

1970 - The Sadtler Standard Spectra, IV n. ${ }^{\circ}$ 37377, UV n..$^{\circ}$ 16599. Sadtler Research Laboratories, Philadelphia.

Wanner, H., Pesakova, M., Baumann, T.W.,

Charubala, R., Guggisberg, A., Hesse, M. \& Schmid, H.

$1975-O(2)$, 1,9-trimethyluric acid and 1,3,7,9tetramethyluric acid in leaves of different Coffea species. Phytochemistry, 14:747-750.

Willaman, J.J. \& Schubert, G.

1961 - Alkaloid-bearing plants and their contained alkaloids. Agricultural Research Service, U.S. Department of Agriculture, Technical Bulletin, 1234:232 